\title{
HUBUNGAN TINGKAT PENGETAHUAN TENTANG DIABETES MELLITUS DENGAN PERILAKU MENGONTROL GULA DARAH PADA PASIEN DIABETES MELLITUS RAWAT JALAN DI RSUD Dr. MOEWARDI SURAKARTA
}

\author{
Kunaryanti' ${ }^{1}$ Annisa Andriyani², Riyani Wulandari ${ }^{3}$ \\ 1Universitas Sebelas Maret Surakarta \\ Email: ${ }^{1}$ kunaryanti@yahoo.com \\ ${ }^{2 \cdot 3}$ Sekolah Tinggi Ilmu Kesehatan (STIKES) 'Aisyiyah Surakarta
}

\begin{abstract}
ABSTRAK
Diabetes Mellitus (DM) merupakan sekelompok kelainan heterogen yang ditandai oleh kenaikan kadar glukosa darah atau hiperglikemia. Perilaku pasien dalam mengontrol gula darah masih buruk, ini dikarenakan pasien belum tahu tentang DM dan mereka masih sering mengkonsumsi makanan dan minuman yang terlalu manis yang tidak sesuai dengan aturan serta perilaku lainnya, sehingga ini mengakibatkan kadar gula darah pasien meningkat. Oleh karena itu, pengetahuan pasien tentang penyakit diabetes mellitus dan terapinya memegang peranan penting dalam mengontrol kadar gula darah. Tujuan dari penelitian ini adalah untuk mengetahui hubungan antara tingkat pengetahuan tentang DM dengan perilaku mengontrol gula darah pada pasien DM Rawat Jalan di RSUD Dr.Moewardi Surakarta. Penelitian ini merupakan penelitian analitik dengan pendekatan cross sectional. Analisa data menggunakan uji chi square. Teknik pengambilan sampel secara quota sampling. Hasil uji bivariat membuktikan pengetahuan tentang DM berhubungan dengan perilaku mengontrol gula darah $(\mathrm{p}=0,000)<0,05$. Kesimpulan dari penelitian ini adalah ada hubungan tingkat pengetahuan tentang DM dengan perilaku mengontrol gula darah pada pasien DM rawat jalan di RSUD Dr. Moewardi Surakarta.
\end{abstract}

Kata kunci : Pengetahuan, Perilaku mengontrol gula darah, Diabetes Mellitus

\begin{abstract}
Diabetes Mellitus (DM) is a group of heterogeneous disorders characterized by an increase in blood glucose levels or hyperglycemia. The poor behavior of patients in controlling blood sugar is due to the lack of knowledge about DM, so they often consume foods and drinks that are too sweet that are not in accordance with the rules. Therefore, the patient's knowledge of DM and its therapy plays an important role in controlling blood sugar levels. The purpose of this study was to determine the relationship between the level of knowledge about DM with blood sugar control behavior in outpatients with diabetes mellitus in Dr.Moewardi Hospital Surakarta. This research was an analytical
\end{abstract}


study with a cross-sectional approach. Data were analyzed using the chi-square test. The sampling technique used was quota sampling. The bivariate test results prove that knowledge of DM was related to blood sugar control behavior $(p=0,000)<0.05$. The conclusion of this study was there is a relationship between the level of knowledge about DM with blood sugar control behavior in outpatient DM patients in Dr. Moewardi Surakarta.

Keywords: Knowledge, blood sugar control behaviour, Diabetes Mellitus

\section{PENDAHULUAN}

Diabetes Mellitus merupakan sekelompok kelainan heterogen yang ditandai oleh kenaikan kadar glukosa dalam darah atau hiperglikemia (Smeltzer \& Bare, 2002). DM dalam dekade sekarang ini menjadi ancaman serius bagi umat manusia di penjuru dunia, bahkan bagi pasien DM penyakit ini merupakan ancaman penyebab kematian. Apabila tidak mendapatkan perawatan segera mungkin akan menyebabkan komplikasi beragam penyakit dalam tubuh (Bangjoni, 2010).

Menurut laporan McCarty dan Zimmet (1994), terdapat minimal 110,4 juta pasien diabetes di dunia dengan prevalensi 1,2-22,0\% untuk orang dewasa, pada tahun 2000 diperkirakan akan meningkat 1.5 kali (menjadi 175,4 juta) dan tahun 2010 meningkat dua kali lipat (menjadi 239,3 juta).

Menurut data WHO, Indonesia menempati urutan ke-4 terbesar dalam jumlah pasien DM di dunia. Pada tahun 2000 yang lalu saja, terdapat sekitar 5-6 juta penduduk Indonesia yang mengidap diabetes. Namun pada tahun 2006 diperkirakan jumlah pasien diabetes di Indonesia meningkat tajam menjadi 14 juta orang, di mana baru $50 \%$ yang sadar mengidap dan diantara mereka baru sekitar 30\% yang datang berobat teratur (Nabyl, 2009).

Pasien Diabetes Mellitus di Provinsi Jawa Tengah pada tahun 2004 berdasarkan laporan program yang berasal dari Rumah Sakit, kasus DM yang ditemukan sebanyak 151.075. DM tertinggi adalah di Kota Semarang yaitu sebesar 46.225 kasus $(30,59 \%)$ dibanding dengan jumlah keseluruhan DM di kabupaten/kota lain di Jawa Tengah dan rata-rata kasus pertahun di Jawa Tengah adalah 4.316,42 kasus (Dinkes Jateng, 2004). Di Jawa Tengah berdasarkan data pola penyakit penderita, puskesmas dan rumah sakit dari berbagai tingkat umur, jumlah kasus DM menempati urutan kedua setelah penyakit neoplasma ganas. Jumlah pasien DM di Surakarta pada tahun 2006 sebanyak 12.818 (Dinkes Jateng, 2006). Jumlah tersebut akan meningkat secara signifikan pada tahun yang akan datang, hal ini dipicu oleh faktor-faktor seperti demografi, gaya hidup yang tidak sehat, lingkungan dan faktor keturunan (Soegondo dkk., 2008).

Berdasarkan hasil studi pendahuluan yang dilakukan oleh peneliti di RSUD Dr. Moewardi Surakarta, bahwa dihasilkan jumlah pasien DM yang dirawat jalan pada tahun 2008 sebanyak 743 orang $(46,9 \%)$ dan jumlah pasien pada tahun 2009 sebanyak 841 orang $(53,1 \%)$, sehingga jumlah pasien DM rawat jalan mengalami peningkatan sebanyak 98 orang (6,2\%) dibanding tahun 2008 (Medical Record RSUD Dr. Moewardi Surakarta, 2010). 


\section{METODE PENELITIAN}

Rancangan penelitian yang digunakan dalam penelitian ini adalah menggunakan metode penelitian Analitik dengan pendekatan cross sectioal. Populasi penelitian adalah pasien DM rawat jalan di RSUD Dr. Moewardi Surakarta pada bulan Januari sampai Agustus 2010 berjumlah 642 pasien, sedangkan jumlah sampel yang digunakan sebanyak 64 pasien dengan teknik pengambilan sampel dalam penelitian ini menggunakan teknik quota sampling. Variabel dalam penelitian ini meliputi variabel Independen yaitu tingkat pengetahuan tentang Diabetes Mellitus, sedangkan variabel dependen dalam penelitian ini adalah perilaku mengontrol gula darah.

\section{HASIL DAN PEMBAHASAN}

\section{Analisa Univariat}

\section{Hasil Gambaran Karakteristik Responden}

Data karakteristik responden dapat dilihat pada Tabel 1.

Tabel 1. Karakteristik responden berdasarkan jenis kelamin, umur, pendidikan, dan pekerjaan $(n=64)$

\begin{tabular}{llll}
\hline No & Karakteristik & $\begin{array}{c}\text { Jumlah } \\
(\mathbf{F})\end{array}$ & $\begin{array}{c}\text { Prosentase } \\
(\mathbf{\%})\end{array}$ \\
\hline 1 & Jenis kelamin & & \\
& Laki-laki & 21 & 32,8 \\
& perempuan & 43 & 67,2 \\
\hline 2 & Umur & 6 & 9,4 \\
& $<40$ tahun & 28 & 43,8 \\
& 40-55 tahun & 30 & 46,9 \\
& >55 tahun & & \\
\hline 3 & Pendidikan & & \\
& SD & 34 & 53,1 \\
& SLTP & 18 & 28,1 \\
& SLTA & 7 & 10,9 \\
& PT & 5 & 7,8 \\
\hline 4 & Pekerjaan & & \\
& PNS & 7 & 10,9 \\
& Wiraswasta & 35 & 54,7 \\
& Tani & 10 & 15,6 \\
& Tidak bekerja & 12 & 18,8 \\
\hline
\end{tabular}

Berdasarkan Tabel 1 dapat diketahui bahwa dari 64 responden sebagian besar berjenis kelamin perempuan yaitu sebanyak 43 pasien $(67,2 \%)$. Karakteristik responden mayoritas berumur $>55$ tahun yaitu sebanyak 30 pasien $(46,9 \%)$. Tingkat pendidikan dari 64 responden sebagian besar mayoritas responden berpendidikan SD yaitu sebanyak 34 pasien $(53,1 \%)$.

Hasil distribusi pekerjaan dari 64 responden pasien Diabetes Mellitus rawat jalan di RSUD Dr. Moewardi Surakarta, mayoritas bekerja sebagai wiraswasta yaitu sebanyak 35 pasien $(54,7 \%)$.

\section{Pengetahuaan Tentang Diabetes Mellitus}

Data tentang frekuensi responden berdasarkan Tingkat pengetahuan tentang diabetes mellitus dapat dilihat pada Tabel 2.

Tabel 2. Frekuensi responden berdasarkan tingkat pengetahuan tentang diabetes mellitus $(n=64)$.

\begin{tabular}{llcc}
\hline No & Pengetahuan & $\begin{array}{c}\text { Jumlah } \\
(\mathbf{F})\end{array}$ & $\begin{array}{c}\text { Prosentase } \\
(\boldsymbol{\%})\end{array}$ \\
\hline 1 & Tinggi & & 68,8 \\
2 & Rendah & & 31.2 \\
\hline
\end{tabular}

Berdasarkan Tabel 2 tersebut diketahui bahwa dari 64 responden pasien Diabetes Mellitus rawat jalan di RSUD Dr. Moewardi Surakarta, mayoritas memiliki pengetahuan yang rendah yaitu sebanyak 44 pasien $(68,7 \%)$.

\section{Perilaku Mengontrol Gula Darah}

Data tentang frekuensi responden berdasarkaan perilaku mengontrol gula darah dapat dilihat pada Tabel 3. 
Tabel 3. Frekuensi responden berdasarkaan perilaku mengontrol gula

\begin{tabular}{|c|c|c|c|}
\hline No & Perilaku & $\begin{array}{l}\text { Jumlah } \\
\text { (F) }\end{array}$ & $\begin{array}{l}\text { Prosentase } \\
(\%)\end{array}$ \\
\hline 1 & Baik & 22 & 34,4 \\
\hline 2 & Buruk & 42 & 65,6 \\
\hline
\end{tabular}

Berdasarkan Tabel 3 tersebut diketahui bahwa dari 64 responden pasien
Diabetes Mellitus rawat jalan di RSUD Dr. Moewardi Surakarta, mayoritas pasien dengan perilaku yang buruk sebanyak 42 pasien $(65,6 \%)$.

\section{Analisis Bivariat}

Berdasarkan Uji Chi Square didapatkan hasil yang dapat dilihat pada Tabel 4.

Tabel 4. Hubungan Tingkat Pengetahuan Tentang Diabetes Mellitus dengan Perilaku Mengontrol Gula Darah

\begin{tabular}{llllccc}
\hline \multirow{2}{*}{ Pengetahuan } & \multicolumn{2}{c}{ Perilaku } & Jumlah & $\chi^{2}$ & $\mathbf{p}$ & OR \\
\cline { 2 - 5 } & Baik & Buruk & & 13,929 & 0,000 & 10,5 \\
\hline Tinggi & 14 & 6 & 20 & & & \\
Rendah & 8 & 36 & 44 & & & \\
\hline Jumlah & 22 & 42 & 64 & & & \\
\hline
\end{tabular}

Analisis pengujian statistik menghasilkan nilai uji chi square $X^{2}$ hitung sebesar 13,929 lebih besar $X^{2}$ tabel $(3,841)$ dengan taraf signifikansi hitung $(\mathrm{p})$ sebesar 0,000. Oleh karena $\mathrm{p}<$ taraf signifikasi tabel sebesar $5 \%(0,05)$ maka hasil tersebut dapat disimpulkan bahwa terdapat hubungan yang signifikan antara pengetahuan tentang Diabetes Mellitus dengan perilaku mengontrol gula darah.

\section{Tingkat Pengetahuan Tentang Diabetes Mellitus pada Pasien Diabetes Mellitus Rawat Jalan di RSUD Dr. Moewardi Surakarta}

Dilihat dari aspek pengetahuan tentang Diabetes Mellitus menunjukan bahwa sebagian besar responden mempunyai tingkat pengetahuan yang rendah tentang Diabetes Mellitus yaitu sebanyak 44 pasien $(68,8 \%)$ dan minoritas responden mempunyai pengetahuan tinggi tentang Diabetes Mellitus sebanyak 20 pasien $(31,3 \%)$, sehingga hal ini dapat disimpulkan bahwa tingkat pengetahuan tentang Diabetes Mellitus pada pasien Diabetes Mellitus rawat jalan di RSUD Dr. Moewardi Surakarta masih rendah. Pengetahuan yang kurang ini salah satunya disebabkan oleh tingkat pendidikan yang rendah. Tingkat pendidikan yang rendah dapat menyebabkan seseorang kesulitan dalam menerima informasi. Penelitian ini didukung Isniati (2007) bahwa di mana jumlah pasien DM yang berpengetahuan rendah atau kurang lebih banyak dari pada yang berpengetahuan tinggi atau baik. Hal ini disebabkan oleh karena pengetahuan tidak hanya diperoleh dibangku pendidikan tapi juga dari pengalaman langsung maupun tidak langsung.

\section{Perilaku Mengontrol Gula Darah pada Pasien Diabetes Mellitus Rawat Jalan di RSUD Dr. Moewardi Surakarta}

Berdasarkan hasil penelitian perilaku mengontrol gula darah menunjukkan bahwa dari 64 responden mayoritas memiliki perilaku yang buruk dalam mengontrol gula darah yaitu sebanyak 42 pasien $(65,6 \%)$ dan minoritas dengan perilaku yang baik yaitu sebanyak 22 pasien $(34,4)$. Hal ini menunjukkan bahwa perilaku mengontrol gula darah pada pasien Diabetes Mellitus rawat jalan di RSUD Dr. Moewardi Surakarta berperilaku buruk dalam mengontrol gula darahnya.

Menurut Badawi (2009) perilaku mengontrol gula darah yang dapat 
dilakukan antara lain dengan perencanaan makan, olahraga teratur, ketaatan mengkonsumsi obat hipoglikemik, dan pemeriksaan gula darah, sehingga peran serta pasien sendiri dan keluarganya sangat penting serta penatalaksanaan dan pengobatan dari tenaga medis, perawat dan ahli gizi. Perilaku dalam mengontrol gula darah dapat diartikan sebagai perilaku pasien dalam mengontrol gula darah secara teratur dengan baik dan benar sesuai dengan anjuran dokter untuk mencegak naiknya gula darah yang melebihi normal dan mencegah komplikasi yang tidak diinginkan.

Perilaku seseorang dipengaruhi oleh tiga faktor yaitu faktor predisposisi yang terwujud dalam pengetahuan, sikap, kepercayaan, faktor pendukung berupa lingkungan dan fasilitas kesehatan dan faktor pendorong yang terwujud dalam sikap dan perilaku petugas kesehatan (Notoatmodjo 2005).

\section{Hubungan Tingkat Pengetahuan Tentang Diabetes Mellitus dengan Perilaku Mengontrol Gula Darah pada Pasien Diabetes Mellitus Rawat Jalan di RSUD Dr. Moewardi Surakarta.}

Hasil penelitian menujukkan bahwa terdapat hubungan yang signifikan antara tingkat pengetahuan tentang Diabetes Mellitus dengan perilaku mengontrol gula darah. Pengetahuan atau kognitif merupakan domain yang sangat penting untuk terbentuknya tindakan seseorang. Pengetahuan diperlukan sebagai dorongan sikap dan perilaku setiap hari, sehingga dapat dikatakan bahwa pengetahuan merupakan stimulus terhadap tindakan seseorang. Mubarak dkk. (2007) mengatakan bahwa perilaku yang didasari pengetahuan akan lebih langgeng daripada perilaku yang tidak didasari pengetahuan.

Penelitian ini sesuai dengan penelitian yang dilakukan oleh Palestin dkk. (2008) yang mengatakan bahwa pengetahuan seseorang erat kaitannya dengan perilaku yang akan diambilnya, karena dengan pengetahuan tersebut ia memiliki alasan dan landasan untuk menentukan suatu pilihan. Kekurangan pengetahuan tentang penyakit yang diderita akan mengakibatkan tidak terkendalinya proses perkembangan penyakit, termasuk deteksi dini adanya komplikasi penyakit.

Adapun menurut Witasari dkk. (2009) pasien berusaha untuk mencari informasi sejelas-jelasnya mengenai penyakitnya, baik dari petugas kesehatan maupun dari media informasi lainnya, sedangkan salah satu faktor yang menentukan perilaku kesehatan seseorang adalah tingkat pengetahuan. Pasien diabetes relative dapat hidup normal bila mengetahui dengan baik keadaan dan cara penatalaksanaan penyakit tersebut.

\section{KESIMPULAN}

Berdasarkan hasil penelitian dan pembahasan pada bab sebelumnya mengenai hubungan tingkat pengetahuan tentang Diabetes Mellitus dengan perilaku mengontrol gula darah pada pasien Diabetes Mellitus rawat jalan di RSUD Dr. Moewardi Surakarta, maka peneliti menyimpulkan bahwa, pasien Diabetes Mellitus yang rawat jalan di RSUD Dr. Moewardi Surakarta dalam penelitian ini paling banyak adalah pasien dengan pengetahuan yang rendah tentang Diabetes Mellitus dan mayoritas pasien Diabetes Mellitus yang rawat jalan di RSUD Dr. Moewardi Surakarta memiliki perilaku yang buruk dalam mengontrol gula darah.

Hasil penelitian ini dari perhitungan uji Chi Square dapat dinyatakan bahwa terdapat hubungan yang signifikan antara pengetahuan tentang Diabetes Mellitus dengan perilaku mengontrol gula darah pada pasien Diabetes Mellitus rawat jalan di RSUD Dr. Moewardi Surakarta. 


\section{DAFTAR PUSTAKA}

Badawi, H. (2009). Melawan Dan Mencegah Diabetes. Araska Printika. Yogyakarta.

Bangjoni. (2010). Bagaimana Mengendalikan Gula Darah Dalam DM. http://bangjoni.dagdigdug.com/2010/04/28/bagaimana-mengendalikan-guladarah-dalam-dm/. Diakses tanggal 4 Maret 2010.

Depkes RI. (2009). Tahun 2030 Prevalensi Diabetes Mellitus Di Indonesia Mencapai 21,3 Juta Orang .Jakarta. http://www.depkes.go.id/inex.php?option $=$ news \&task+viewarticle $\&$ sid $=3613 \&$ itemid= $=2$. Diakses tanggal 8 Februari 2010.

Dinkes Jateng. (2004). Profil Kesehatan Propinsi Jawa Tengah Tahun 2004. http://www.Dinkesjatengprov.go.id/dokumen/profil/profile2004/bab4.htm\#1.

Diakses tanggal 12 Maret 2010.

Dinkes Jateng. (2006). Profil Kesehatan Propinsi Jawa Tengah Tahun 2006. Dinas Kesehatan Provinsi Jawa Tengah.

Isniati. (2007). "Hubungan Tingkat Pengetahuan Penderita DM dengan Keterkendalian Gula Drah di Poliklinik RS Perjan Dr. M. Djamil Padang". Jurnal Kesehatan Masyarakat, Volume 1, No. 2, September 2007, hal. 72-78. doi.org/10.24893/jkma.1.2.73-77.2007.

McCarty, D \& Zimmet, P. (1994). Diabetes 1994+2010: global estimates and projections. Bayer AG, Leverkusen and International Diabetes Institute, Melbourne.

Mubarak, I. W, Chayatin, N., Rozikin, K., dan Supradi. (2007). Promosi Kesehatan sebuah Pengantar Proses Belajar Mengajar Dalam Pendidikan. Graha Ilmu. Yogyakarta.

Nabyl, R. A. (2009). Cara Mudah Mencegah Dan Mengobati Diabetes Mellitus. Aulia Publishing. Yogyakarta.

Notoadmodjo, S. (2003). Ilmu Kesehatan Masyarakat. Rineka Cipta. Jakarta. 
. (2005). Pendidikan dan Perilaku Kesehatan. Rineka Cipta. Jakarta.

(2007). Promosi Kesehatan Dan Ilmu Perilaku. Rineka Cipta. Jakarta.

Smeltzer, S. C., \& Bare, B. G. (2002). Buku Ajar Keperawatan Medikal Bedah. (Vol. 2). EGC. Jakarta.

Soegondo, S., Sarwono, P., dan Subekti, I. (2008). Penatalaksanaan Diabetes Mellitus Terpadu. FKUI. Jakarta.

Soegondo, S., dan Sukardji, K. (2008). Hidup Secara Mandiri Dengan Diabetes Mellitus Kencing Manis Sakit Gula. FKUI. Jakarta.

Witasari, U., Rahmawaty, S., \& Zulaekah, S. (2009). Hubungan tingkat pengetahuan, asupan karbohidrat, dan serat dengan pengendalian kadar glukosa darah pada penderita diabetes melitus tipe 2. Jurnal Penelitian Sains \& Teknologi, 10(2), $130-138$ 
Jurnal Kesehatan. ISSN 1979-7621 (Print). ISSN 2620-7761 (Online). Vol. 11. No. 1. Juni 2018 